\title{
Perception of eye care services among patients attending mercy eye centre, Abak
}

\begin{abstract}
Background: The assessment of patients' 6 perception of eye care services is an important tool for achieving excellence in eye care service delivery.
\end{abstract}

Objectives: To determine the perception of eye care service delivery, personnel and facility among patients attending a mission hospital in a rural community in Nigeria.

Methods: This was a hospital based cross-sectional study. Ethical approval was obtained and 127 consecutive consenting patients were selected. Data were obtained using a pre tested structured questionnaire and analysed using SPSS version 21.0.

Results: Most of the participants (79.5\%) were generally satisfied with the eye care services. The main areas of dissatisfaction were the waiting time, cost of services and the number of doctors. Areas with high satisfaction levels include attitude of the staff, examination and consultation with doctors and outcome of treatment. Majority (94.5\%) of the participants would like to return to/continue with the hospital for their eye care services.

Conclusion: The findings of the study show that there is need for improvement in the areas of waiting time, cost of services and the number of doctors in order to provide better eye care services in the hospital.

Keywords: heterogeneous, eye care services, hospital pharmacy, prescribed drugs
Volume 7 Issue 2 - 2017

\author{
Chinawa Ndubuisi Elijah,' ${ }^{\text {Chime }}$ AA $^{2}$ \\ 'University of Uyo Teaching Hospital Uyo/Siloam Eye \\ Foundation, Nigeria \\ ${ }^{2}$ University of Nigeria Teaching Hospital Enugu, Nigeria
}

Correspondence: Chinawa Ndubuisi Elijah, University of Uyo Teaching Hospital/Mercy Hospital Abak, Nigeria, Email favouredchinawa@gmail.com

Received: June 12, 2017 | Published: July 19, 2017

\section{Introduction}

Patients' judgement and feedback regarding eye care service are vital in organization and implementation of changes within the service. ${ }^{1}$ They serve to complement evaluations conducted from the point of view of the health professionals and public health authorities. $^{2}$ Assessing the patients' perception aim at striking a balance between the expectations of the patients and the quality of services rendered by the eye care team. It is a yardstick that measures the success of the available services. ${ }^{3}$ The goal of any service provider is to create satisfaction among the consumers. ${ }^{3}$ The patient is the ultimate consumer in the eye care setting, ${ }^{3}$ and is said to be the most important person in the system. ${ }^{4}$ Thus, the eye care system should aim at adopting a patient oriented system to ensure maximum patient satisfaction. ${ }^{4}$ Patients' perception of eye care services is a reflection of their satisfaction and has been noted to vary from that of the service providers. ${ }^{5}$ Determinants of patients' overall satisfaction with received care have been noted to include the medical aspects of care such as trained personnel, use of appropriate medication and proper instruments, and the use of newer technologies; ${ }^{4}$ as well as the non-medical aspect of care such as waiting time, assess to available services and communication. ${ }^{4}$

Eye care services just like other health care services are people based and are therefore said to be heterogeneous in nature. They vary depending on factors such as the environment, the mood of both the service provider and receiver. In other words eye care providers vary in the way they handle the same illness and patients vary in their opinion of the same eye care providers. ${ }^{3}$ In a study by AdemolaPopoola et al., ${ }^{6}$ on Patients' Assessment of Quality of Eye Care in a Nigerian Teaching Hospital in north-central Nigeria, long waiting time was found to be a major source of dissatisfaction to the patients.
This finding is in keeping with that of Sudhan et al., ${ }^{7}$ While studying patient satisfaction regarding eye care services at tertiary hospital of central India. Ezegwui et al., ${ }^{5}$ noted that the cost of services was a major source of dissatisfaction while studying Patients' satisfaction with eye care services in a Nigerian teaching hospital in south-east Nigeria. This is at variance with the finding of Ademola-Popoola et al., ${ }^{6}$ where most of the patients perceived the cost of services to be affordable.

Sudhan et al., ${ }^{7}$ also noted that most of the participants were highly satisfied with the attitude of the eye care personnel. In another study by Ghosh in India, communication and behaviour of the nurses were described as pleasant and satisfactory in $46 \%$ and $32 \%$ of the cases respectively, while $84 \%$ of participants perceived the efficiency of the doctors to be satisfactory. ${ }^{3}$ Patients' satisfaction with eye care services will determine their continued use of the facility. ${ }^{5}$ It has therefore been recommended that surveys analysing the satisfaction of patients be carried out regularly as a means of assessing and improving the eye care services being offered to the patients. ${ }^{5,7}$ This study is therefore aimed at determining the perception of eye care services among patients by analysing their satisfaction with eye care delivery, personnel and facility with a view to improving the quality of eye care services offered and making the system more patient oriented for better patient satisfaction.

\section{Materials and methods}

This was a descriptive cross-sectional study, carried out at Mercy Eye Centre, which is a section of the Mercy Hospital, a mission hospital in Abak. The eye section has two consultant Ophthalmologists while resident doctors come in batches of 1-3 for surgical experience. Abak is a rural community located in Abak Local Government Area of Akwa-Ibom State, Nigeria. It has a landmass of $190 \mathrm{~km} 2$, and its 
geographical coordinates are latitude $4^{\circ} 59^{\prime} \mathrm{N}$ and longitude $7^{\circ} 47^{\prime} \mathrm{E}$ It is located in the tropical rain forest belt of south-south Nigeria. The study population consisted of consecutive patients visiting the Eye Centre during the period of the study, until the sample size was completed.

The sample size was calculated using the formula:

$$
n f=\frac{n}{1+n / N}
$$

Where,

$\mathrm{n}_{\mathrm{f}}=$ Desired sample size when the population is less than 10,000 .

$\mathrm{n}=$ The desired sample size when the population is more than $10,000=146$ (which was calculated using a prevalence of $10.6 \%,{ }^{6}$ which is the percentage of people satisfied with the waiting time.)

$\mathrm{N}=$ the estimate of the population size $=1000$

Substituting in the equation,

$$
\begin{array}{r}
n f=146 \\
1+\frac{146}{1000} \\
=\frac{146}{1.146} \\
\approx 127
\end{array}
$$

Ethical approval was obtained from the Health Research Ethics Committee of the hospital before commencement of the study. In the course of the study, the tenets of the Helsinki declaration and the National code of Health research were adhered to. The purpose and benefits of the study were explained to the participants in details and an informed consent obtained from each participant before being included in the study. Confidentiality was also guaranteed. All consenting consecutive patients attending the eye clinic in December 2016 were recruited into the study until the estimated sample size was attained. Those who did not give consent were excluded from the study.

A pre tested structured was used to obtain data. The questionnaire was made up of five sections, A B, C D and E. Section A was used to collect the demographic data of the participants, their perception of eye care delivery process, eye care personnel and the eye care facility were recorded in sections $\mathrm{B}, \mathrm{C}$ and $\mathrm{D}$; while section $\mathrm{E}$ was used to compare the facility with other eye care facilities. The authors and a trained assistant administered the questionnaire. Data was coded and double entered into a computer and analyzed using Statistical Package for Social Sciences version 21.0 Chicago, Illinois, USA. All statistical calculations were done at the significance of $P<0.05$. Chi-square was used for the test of significance.

\section{Results}

A total of 127 consecutive consenting patients were interviewed. The age range was from 18-85years and the mean age $48.13 \pm 17.02$ years. The demographic data of the participants are shown in (Table 1). Concerning the perception of eye care delivery by the participants, more than half of them $67(52.8 \%)$ felt they waited too long to see the doctor, $10(7.9 \%)$ were undecided while $50(39.4 \%)$ felt otherwise. Most of the participants $88(69.3 \%)$ noted that the drugs prescribed for them by the doctors were usually available in the hospital,
$18(14.2 \%)$ said theirs were usually unavailable, while $21(16.5 \%)$ were unsure. Only $18(14.2 \%)$ felt the medical treatment they received was inadequate, $89(70.1 \%)$ felt the medical treatment was adequate,

\begin{tabular}{|c|c|c|}
\hline Sex & Frequency & Percent \\
\hline Male & 69 & 54.3 \\
\hline Female & 58 & 45.7 \\
\hline Total & 127 & 100.0 \\
\hline Marital status & Frequency & Percent \\
\hline Single & 48 & 37.8 \\
\hline Married & 64 & 50.4 \\
\hline Divorced & I & .8 \\
\hline Widowed & 14 & 11.0 \\
\hline Total & 127 & 100.0 \\
\hline Educational Status & Frequency & Percent \\
\hline Primary & 29 & 22.8 \\
\hline Secondary & 40 & 31.5 \\
\hline Tertiary & 49 & 38.6 \\
\hline None & 9 & 7.1 \\
\hline Total & 127 & 100.0 \\
\hline Occupation & Frequency & Percent \\
\hline Trading & 40 & 31.5 \\
\hline Farming & 21 & 16.5 \\
\hline Artisan & 3 & 2.4 \\
\hline Driver & 2 & $\mathrm{I} .6$ \\
\hline Others & 16 & 12.6 \\
\hline Civil Servant & II & 8.7 \\
\hline Pensioneer & 10 & 7.9 \\
\hline Buss. Man & 3 & 2.4 \\
\hline Clergy & 5 & 4.0 \\
\hline Fishing & I & .8 \\
\hline Public Servant & 2 & 1.6 \\
\hline Student & 9 & 7.1 \\
\hline Teaching & 4 & 3.2 \\
\hline Total & 127 & 100.0 \\
\hline Nationality & Frequency & Percent \\
\hline Nigerian & 127 & 100 \\
\hline Tribe & Frequency & Percent \\
\hline Adoni & 2 & 1.6 \\
\hline Annang & 39 & 30.7 \\
\hline Efik & I & .8 \\
\hline Epie & 2 & 1.6 \\
\hline Ibibio & 36 & 28.3 \\
\hline Idoma & 3 & 2.4 \\
\hline Igbo & 26 & 20.5 \\
\hline ljaw & 10 & 7.9 \\
\hline Ogoni & 6 & 4.7 \\
\hline Oron & I & .8 \\
\hline Yoruba & 1 & .8 \\
\hline Total & 127 & 100.0 \\
\hline Religion & Frequency & Percent \\
\hline Christianity & 127 & 100.0 \\
\hline
\end{tabular}
while $20(15.7 \%)$ were uncertain. Of the $33(26.0 \%)$ that have had surgery in the hospital, only $4(12.1 \%)$ felt the outcome was poor while 29(87.9\%) felt their outcome was good.

Table I Demographic data of the participants 
Regarding the perception of the eye care personnel by the participants, $107(84.3 \%$ ) felt they were compassionate and supportive, $10(7.9 \%)$ felt they were not, while the remaining $10(7.9 \%)$ were undecided. Most of the participants 108 (85.0\%) felt the eye care personnel were honest, $9(7.1 \%)$ felt otherwise while $10(7.9 \%)$ were uncertain. Majority $110(86.6 \%)$ also felt the eye care personnel were respectful, $8(6.3 \%)$ were unsure while $9(7.1 \%)$ felt otherwise. Only $16(12.6 \%)$ felt they were not adequately examined by the doctors, $8(6.3 \%)$ were unsure while $103(81.1 \%)$ felt otherwise. With regards to the time allowed for discussion in view of the patients' eye condition, 98(77.2\%) felt sufficient time was allowed, 21(16.5\%), felt the time was insufficient while $8(6.3 \%)$ were unsure. A few of the participants $20(15.7 \%)$ felt the eye care personnel gave inadequate information concerning their eye problems, most $97(76.4 \%)$ felt the information they were given was adequate while $10(7.6 \%)$ were uncertain. More than half of the participants $71(55.9 \%)$ felt their appointments were not too often while $31(24.4 \%)$ felt their appointments were too often, $25(19.7 \%)$ were undecided.

(Figures $1 \& 2$ ) show the duration the patients have been coming to the hospital and the frequency of their appointments respectively. The participants visit the hospital from various states of the country as shown in (Table 2). The time it takes to get to the hospital from the location of the participants is as shown in (Table 3). Most participants, $103(81.1 \%)$ felt the location of the hospital was adequate, $7(5.5 \%)$ were not certain, while $17(13.4 \%)$ felt it was not adequate. More than half of the participants, $67(52.8 \%)$ felt the hospital fees were affordable, 39(30.7\%) felt they were not, 21(16.5\%) were uncertain. Only a few, $16(12.6 \%)$ felt the payment process was not easy and straight forward, $99(78.0 \%)$ felt otherwise. Up to $42(33.1 \%)$ felt the number of doctors was inadequate, while $53(41.7 \%)$ felt there were enough doctors. A few $18(14.2 \%)$ felt the eye care equipment were not adequate, while $82(64.6 \%)$ felt they were. Only 19(15\%) felt the number and sizes of rooms were not adequate, 75(59.1\%) felt they were. Generally, most of the participants $101(79.5 \%)$ felt the eye care services rendered were adequate, $10(7.9 \%)$ felt they were not while 16(12.6\%) were uncertain. Almost all the participants $120(94.5 \%)$ would like to return or continue with the hospital for their eye care services, $4(3.1 \%)$ would not like to, while $3(2.4 \%)$ were uncertain.

\section{DURATION OF PATIENTS' HOSPITAL VISIT}
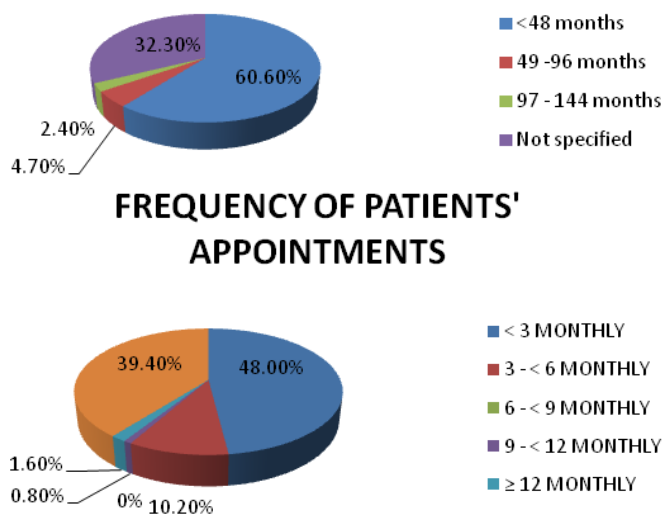

$$
\begin{aligned}
& \square<3 \text { MONTHLY } \\
& \square 3-<6 \text { MONTHLY } \\
& \square 6-<9 \text { MONTHLY } \\
& \square 9-<12 \text { MONTHLY } \\
& \square \geq 12 \text { MONTHLY }
\end{aligned}
$$

Figure I \& $\mathbf{2}$ The duration the patients have been coming to the hospital and the frequency of their appointments respectively.
Table 2 Locations where the patients come from for their appointments

\begin{tabular}{lll}
\hline & Frequency & Percent \\
\hline Akwa Ibom & 87 & 68.5 \\
Rivers State & 28 & 22 \\
Abia State & 3 & 2.4 \\
Bayelsa & 4 & 3.1 \\
Cross R & 1 & 0.8 \\
Imo & 4 & 3.1 \\
Total & 127 & 100
\end{tabular}

Table 3 Duration from participant's location to the hospital

\begin{tabular}{lll}
\hline & Frequency & Percent \\
\hline$<2 \mathrm{hrs}$ & 69 & 54.3 \\
$2 \mathrm{hrs}-<4 \mathrm{hrs}$ & 39 & 30.7 \\
$4 \mathrm{hrs}-<6 \mathrm{hrs}$ & $1 \mathrm{I}$ & 8.7 \\
not specified & 8 & 6.3 \\
Total & 127 & 100 \\
\hline
\end{tabular}

Some of the participants, $56(44.1 \%)$ have visited other hospitals, of these, only $8(14.3 \%)$ have visited a mission hospital just like ours, $24(42.9 \%)$ each have been to government and private hospitals. Of the participants that have visited other hospitals, 24(42.9\%) each feel the waiting time is shorter and longer while $8(14.3 \%)$ feel it is the same. More people, 25(44.6\%) feel the treatment is cheaper here, 21(37.5\%) feel it is costlier, while $10(17.9 \%)$ feel it is the same. The perception of the participants regarding the effectiveness of our treatment, proficiency and attitude of our staff compared to other hospitals visited is shown in (Figure 3).

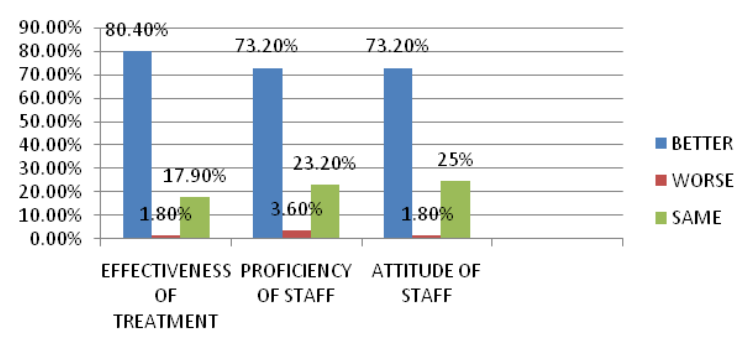

Figure 3 Proficiency and attitude of our staff compared to other hospitals visited.

Of the 101 participants who felt the eye care service rendered in the hospital was adequate, $98(97.0 \%)$ would like to continue/return to the centre for eye care $(\mathrm{p}=0.03)$. A hundred $(97.1 \%)$ of the 103 who felt the facility was adequately located would like to continue/return for their eye care, while $16(94.1 \%)$ out of 17 people that felt otherwise would also like to continue/return for their eye care $(p=0.00)$. Of the 67 that felt the fees were affordable, 63(94.0\%) would like to continue/return for eye care, but this was not statistically significant $(p=0.33)$. Eighty-six $(86.9 \%)$ of the 99 that felt the process of payment was easy and straight forward felt that the services rendered were generally adequate, while $62.5 \%$ of those that felt the process of payment was not easy and straight forward also felt that the services 
rendered were generally adequate $(\mathrm{p}=0.00)$. All those who felt that the number of doctors was inadequate would still like to continue/return for eye care, while $92.5 \%$ of those who felt the number of doctors was adequate would also like to continue/return for eye care but this was not statistically significant $(\mathrm{p}=0.39)$.

Although $88.1 \%$ of those who felt the number of doctors was inadequate also felt they were usually adequately examined by the doctors, this was not statistically significant $(\mathrm{p}=0.05)$. Similarly, all those who felt their surgical outcome was not good would still like to continue/return for eye care but this was not statistically significant ( $p$ $=0.86$ ). Of those who felt the medical treatment given by the doctors was inadequate, $94.4 \%$ would still like to continue/return for eye care while $97.8 \%$ of those who felt the medical treatment was adequate would also like to continue/return for eye care and this was statistically significant $(p=0.03)$, of the 67 who felt they waited too long to see the doctor, $73.1 \%$ still felt the services rendered were generally adequate and $95.5 \%$ of the 67 would like to continue/return for eye care but these were not statistically significant ( $\mathrm{p}=0.24$ and 0.53 respectively).

\section{Discussion}

Constant evaluation of patients' perception of eye care services is paramount to achieving excellence in eye care delivery. This study aims at assessing the patients' perception of eye care service delivery, personnel and facility.

\section{Perception of eye care delivery}

More than half of the participants (52.8\%) reported long waiting time. This is more than the $30.3 \%$ reported by Ezegwui et al. ${ }^{5}$ in southeastern Nigeria, and $37.8 \%$ by Rizyal., ${ }^{8}$ archers. ${ }^{1,69}$ The long waiting time may be attributed to the high patient load with few eye care personnel to attend to them. Most of the participants were satisfied with both the medical $(70.1 \%)$ and surgical $(87.9 \%)$ treatment they received. This compares with the $79.3 \%$ of patients who were satisfied with their surgical outcome in a study by Patel et al., ${ }^{10}$ Well above half of the participants, $69.3 \%$ noted that their prescribed drugs were available in the hospital pharmacy. This is similar to the $64.3 \%$ reported by Sagaro et al., ${ }^{11}$ who were able to buy their prescribed drugs from the hospital pharmacy. On the contrary, some researchers, ${ }^{6,12}$ have noted availability of drugs as a major dissatisfaction area as up to $60 \%$ and $70 \%$ were reported to source for prescribed drugs from outside the hospital. Although $78.0 \%$ of the participants agreed the payment process was easy and straight forward, only $52.8 \%$ feel the fees are affordable. Cost of services constitutes a major dissatisfaction area for the patients in this study. In a study by Ezegwui et al., ${ }^{5}$ where only $6.2 \%$ of the patients were satisfied with the cost of services, cost was also noted as a major dissatisfaction area. However, some other researchers, ${ }^{6,9}$ have reported higher satisfaction levels in contrast to our findings.

\section{Perception of eye care personnel}

Most of the patients interviewed feel the staff are compassionate and supportive $(84.3 \%)$, honest $(85.0 \%)$, and respectful $(86.6 \%)$ and therefore satisfied with the general attitude of the staff. This is in keeping with the findings by other researchers in Asia. ${ }^{1,3,7,8,10}$ However, Ezegwui et al., ${ }^{5}$ noted attitude of the staff as a major area of dissatisfaction in their study. It has been noted that patient information and communication are some of the areas that must be addressed in other to improve eye care services [4]. In our study, $77.2 \%$ feel sufficient time is allowed for discussions in view of their eye conditions, and $76.4 \%$ feel they receive adequate information from the eye care personnel concerning their eye problems. This compare to the $83.6 \%$ reported by Ademola-Popoola et al. ${ }^{6}$ as those who rated the explanation given to them by the health workers as good. Although only $41.7 \%$ feel the number of doctors is adequate, $81.1 \%$ feel they are usually adequately examined by the doctors during consultation.

\section{Perception of eye care facility}

Majority of the patients, $68.5 \%$ visit the hospital from within Akwa Ibom state, the rest come from areas around the state. In as much as a significant number of patients $(31.5 \%)$ come from outside the state, it takes most of them $(85.0 \%)$ less than 4hours to get to the hospital. Although up to $39.4 \%$ of the patients spend $\geq 2$ hours on the road to get to the hospital, $81.1 \%$ still feel the location of the hospital is adequate, and therefore easily accessible. This may be explained by the fact that most of the patients reside within the state. Easy accessibility has been noted as an important factor that must be considered for better service delivery. ${ }^{4}$ Although most of the patients $58.2 \%$ have their appointments as often as $\leq 6$ monthly, $55.9 \%$ are satisfied with the frequency of their appointments. The use of appropriate equipment and instrument is an important medical component of patient care. ${ }^{4}$ In our study, $64.6 \%$ of the participants noted that the eye care equipment were adequate. The physical facilities such as the number of consulting rooms were noted to be adequate by $59.1 \%$ of the participants. Ezegwui et al., ${ }^{5}$ also noted physical facilities to be a major dissatisfaction area in their study.

The major areas of dissatisfaction noted in our study are the waiting time, cost of treatment and number of doctors. Despite these challenges $79.5 \%$ of the participants were generally satisfied with the services provided by the hospital. Other researchers, ${ }^{5,6,9}$ have reported even higher levels of general satisfaction. Of the participants who have visited other hospitals for eye care, $80.4 \%$ feel our treatment is more effective, $73.2 \%$ feel our staff are more proficient and $73.2 \%$ feel our staff have better attitude. This will explain the reason $94.5 \%$ would like to continue/return to our hospital for eye care. This compares to the $90.9 \%$ reported by Ezegwui et al. ${ }^{5}$ as those that would like to return for eye care.

\section{Conclusion}

Patients' perception of eye care services is dynamic. Periodic monitoring and evaluation of quality of eye care from patients' view will serve as a good audit tool to ensure continuous quality improvement. This study has highlighted some areas of need which should be focused on in an attempt to improve eye care services in the hospital.

\section{Acknowledgments}

None

\section{Conflicts of interest}

The author declares that there are no conflicts of interest.

\section{References}

1. Alahmari M, Aljasser I, Sasidhar B. Patient Satisfaction and Perception of Quality of Care in Outpatient Clinic in an Eye Specialist Hospital in Saudi Arabia. Br J Econ Manag Trade. 2015;10(4):1-8. 
2. Haddad S, Fournier P, Potvin L. Measuring Lay People's Perceptions of the Quality of Primary Health Care Services in Developing Countries. Validation of a 20-Item Scale. Int J Qual Health Care. 1998;10(2):93104.

3. Sudip Ghosh. An Analytical Study on Patients Satisfaction and Medical Facilities Provided by Public Hospital: With Special Reference to Dhubri Civil Hospital, Jhagrarpar. Int J Healthc Sci. 2014;2(1):107-115.

4. How Can We Improve Patient Care. Community Eye Health. 2012;15(41):1-3.

5. Ezegwui I, Okoye O, Aghaji A, et al. Patients' Satisfaction with Eye Care Services in a Nigerian Teaching Hospital. Niger J Clin Pract. 2014;17(5):585-588.

6. Ademola-Popoola DS, Akande TM, Idris A. Patients' Assessment of Quality of Eye Care in a Nigerian Teaching Hospital. Niger Postgrad Med J. 2005;12(3):145-148.

7. Sudhan A, Khandekar R, Deveragonda S, et al. Patient Satisfaction Regarding Eye Care Services at Tertiary Hospital of Central India. Oman J Ophthalmol. 2011;4(2):73-76.
8. Rizyal A. Patients' Satisfaction with Eye Care Services at Nepal Medical College. Nepal Med Coll J. 2012;14(3):172-175.

9. Iliyasu Z, Abubakar IS, Abubakar S, et al. Patients' Satisfaction with Services Obtained from Aminu Kano Teaching Hospital, Kano, Northern Nigeria. Niger J Clin Pract. 2010;13(4):371-378.

10. Patel KJ, Kapadia PR, Chaudhari VP, et al. Perception of Cataract Patients Regarding Health Care Services at Tertiary Care Hospital. Community Med. 2015;6(4):605-608.

11. Sagaro GG, Yalew AW, Koyira MM. Patients' Satisfaction and Associated Factors Among Outpatient Department at Wolaita Sodo University Teaching Hospital, Southern Ethiopia: A Cross Sectional Study. Sci J Clin Med. 2015;4(5):109-116.

12. Assefa F, Mosse A, Hailemichael Y. Assessment of Clients' Satisfaction with Health Service Deliveries at Jimma University Specialized Hospital. Ethiop J Health Sci. 2011;21(2):101-109. 